\title{
AVALIAÇÃO DAS CONDIÇÕES DE TRABALHO, TREINAMENTO, SAÚDE E SEGURANÇA DE BRIGADISTAS DE COMBATE A INCÊNDIOS FLORESTAIS EM UNIDADES DE CONSERVAÇÃO DO DISTRITO FEDERAL - ESTUDO DE CASO ${ }^{1}$
}

\author{
Nilton César Fiedler², Thiago Oliveira Rodrigues ${ }^{3}$ e Marcelo Brilhante de Medeiros ${ }^{4}$
}

\begin{abstract}
RESUMO - Este estudo teve como objetivo avaliar as condições de trabalho, treinamento, saúde e segurança dos brigadistas de combate a incêndios florestais no Distrito Federal. A pesquisa foi realizada nas Unidades de Conservação da Fazenda Água Limpa, Reserva Ecológica do Instituto Brasileiro de Geografia e Estatística e Instituto Jardim Botânico de Brasília. A coleta de dados foi feita com a aplicação de um questionário em forma de entrevista individual. Participaram da avaliação todos os 53 brigadistas das Unidades de Conservação. De acordo com os resultados, a brigada do Jardim Botânico de Brasília tinha significativo porcentual de treinados (92,8\%), todos com cursos de primeiros socorros, e um alto porcentual de trabalhadores com problemas de saúde (33,3\%). Os brigadistas da Reserva Ecológica do IBGE exerciam, em sua grande maioria, o trabalho por gosto pela atividade $(84,6 \%)$, eram bem treinados $(92,3 \%)$ e todos participaram de cursos de primeiros socorros, sendo o porcentual de acidentes o mais baixo (7,7\%). Na brigada da Fazenda Água Limpa foram encontrados os menores porcentuais de treinados (39,1\%), maiores porcentuais de acidentes $(17,4 \%)$, menores porcentuais de pessoas que exerciam a função por gosto pela atividade $(30,4 \%)$ e menores porcentuais de pessoas com problemas de saúde (8,7\%). A grande maioria dos brigadistas nas três Unidades de Conservação ressaltou a questão da necessidade de regulamentação das brigadas e atentou para a insatisfação quanto aos equipamentos de proteção individual utilizados e inadequada reposição.
\end{abstract}

Palavras-chave: Condições de trabalho e incêndios florestais.

\section{EVALUATION OF JOB CONDITIONS AND ASPECTS RELATED TO TRAINING, HEALTH AND SAFETY OF THE FOREST FIRE CREW MEMBERS AT DISTRITO FEDERAL}

\begin{abstract}
The objective of this work was to evaluate the job conditions and aspects related to training, health and safety of forest fire crew members at Distrito Federal. The work was carried out in some Protected Areas including Água Limpa Farm, Ecological Reserve of Brazilian Institute of Geography and Statistics (IBGE) and Brasília Botanical Garden. The data was collected through individual interviews with 53 fire crew members. The results showed that the fire crew members of Brasília Botanical Garden had a high number of trained workers for forest fires (92,8\%), all members obtained first aid courses and there was a high number of health problems (33,3\%). The fire crew members of IBGE Ecological Reserve showed a high percentage of satisfaction with the activity (84,6\%) and forest fire training (92,3\%), all members obtained first aid courses and there was a low accident rate (7,7\%). At Água Limpa Farm there were few fire crew members with training $(39,1 \%)$, high percentage of accidents $(17,4 \%)$ and low percentage of health problems $(8,7 \%)$. Most of the fire crew members in the three Protected Areas showed dissatisfaction with the equipment and job regulations.
\end{abstract}

Keywords: Job conditions and forest fires.

\footnotetext{
${ }^{1}$ Recebido em 07.11.2003 e aceito para publicação em 10.11.2005.

${ }^{2}$ Departamento de Engenharia Rural do Centro de Ciências Agrárias -UFES - Alegre -ES. E-mail: <fiedler@pesquisador.cnpq.br> .

${ }^{3}$ Engenheiro Florestal - UnB - Caixa Postal 04357, 70910-900 Brasília-DF.

${ }^{4}$ EMBRAPA - CENARGEN - Brasília-DF. E-mail: <medeiros@cenargen.embrapa.br>.
} 


\section{INTRODUÇÃO}

Os incêndios florestais geram diversos prejuízos econômicos e paisagísticos, ecológicos, podendo ocorrer em Unidades de Conservação, áreas de preservação, fazendas, margens de estradas, proximidades de aglomerados urbanos e áreas de reflorestamento, dentre outras localidades.

No Brasil, inicialmente os incêndios florestais eram combatidos principalmente por voluntários, bombeiros, militares e funcionários de Unidades de Conservação e empresas de reflorestamento. A partir da década de 1990 foram formados os primeiros brigadistas civis de combate aos incêndios florestais em Unidades de Conservação, com treinamento e equipamentos baseados em modelos dos EUA, do Canadá, do Chile e de outros países (MEDEIROS e FIEDLER, 2004).

Diante das perdas anuais decorrentes do fogo, há a necessidade de mobilização de equipamentos e pessoal para o combate. Na ocorrência de fogo no Distrito Federal, normalmente os combatentes, ou brigadistas, não raramente trabalham em locais de difícil acesso e locomoção, além de serem submetidos freqüentemente a jornadas estafantes, utilizando equipamentos em quantidade insuficiente ou de eficiência duvidosa para o tipo de combate a ser travado (MEDEIROS, 2002). Essas características delineiam um quadro de possível estresse físico e mental, o qual vem tendo pouco ou nenhuma atenção da comunidade científica, sendo normalmente negligenciado. No entanto, um interesse muito maior é depositado na criação e desenvolvimento de equipamentos, legando o homem a um segundo plano, embora este seja o usuário final dos equipamentos e ferramentas.

O combate a incêndios florestais é uma atividade notoriamente desgastante. Aliado a todo o desgaste físico, se as condições de trabalho forem precárias, haverá comprometimento dos níveis de saúde, segurança, bem-estar e satisfação do trabalhador. Esse comprometimento poderá levar a altos índices de acidentes do trabalho, surgimento de doenças relacionadas ao trabalho, insatisfação, baixa qualidade e produtividade dos serviços. Para que um combate seja eficaz é necessário, acima de tudo, que os brigadistas estejam bem treinados, equipados e que as condições de trabalho sejam desejáveis. Em avaliação de brigadistas de combate a incêndios florestais, Fiedler et al. (2004) concluíram que os elevados riscos de acidentes no trabalho podem ser minimizados com o treinamento e reciclagem constantes, fornecimento e utilização de equipamentos de proteção individual e estabelecimento de normas que minimizem os riscos de acidentes. Fiedler e Medeiros (2004) observaram no Parque Nacional da Serra da Canastra a necessidade de aumentar consideravelmente a carga horária e as disciplinas dos cursos regulares destinados às brigadas para a obtenção de melhores resultados.

Para atingir um nível desejável de treinamento, uma brigada deve buscar essencialmente o condicionamento físico e o conhecimento das técnicas e métodos de combate, juntamente com o conhecimento do comportamento do fogo em resposta às condições da região onde a brigada atua (SILVA et al., 2003).

O objetivo desta pesquisa foi avaliar as condições de trabalho, treinamento, saúde e segurança dos brigadistas de combate a incêndios florestais em Unidades de Conservação do Distrito Federal.

\section{MATERIAL E MÉTODOS}

\section{1. Área de estudo}

A pesquisa foi realizada em uma área de cerrado, um dos cinco maiores tipos de vegetação do Brasil, cobrindo aproximadamente 2 milhões de $\mathrm{km}^{2}$, com clima tropical (Köppen Aw e Cwa nas regiões do sul) e precipitação anual média entre 1.110 e 1.600 mm. Cerca de $90 \%$ da precipitação está distribuída na estação chuvosa (outubro a abril). Nessa região, existe uma estação seca bem definida que vai de maio a setembro (MIRANDA et al., 1996). A temperatura média nos meses de maior atuação dos brigadistas (maio a outubro) na região varia entre 18 e $25^{\circ} \mathrm{C}$. A umidade relativa do ar varia entre 20 e $60 \%$, com mínimas chegando a $15 \%$ nas horas mais quentes do dia.

A coleta de dados foi feita numa área total de 10.629,63 hectares, na região da APA Gama Cabeça-de-Veado, dentro da Reserva Ecológica do IBGE, Fazenda Água Limpa da Universidade de Brasília e Jardim Botânico de Brasília, localizados entre as coordenadas 1555'58”'S e $47^{\circ} 51^{\prime} 02^{\prime \prime}$ 'W, onde estão presentes as fisionomias vegetais de campo limpo, campo sujo, cerrado sensu stricto, cerradão e matas de galeria. 


\subsection{População e amostragem}

A população amostrada foi composta por todos os funcionários (53) das três brigadas de combate a incêndios florestais que atuavam nessas áreas, sendo levantados por meio de questionários. Os questionários foram aplicados por meio de entrevistas individuais aos brigadistas.

\subsection{Fatores estudados}

Os questionários versaram sobre os fatores humanos, as condições de saúde, alimentação, treinamento, reciclagem e segurança no trabalho. A aplicação dos questionários foi realizada utilizandose a metodologia proposta por Fiedler (1998). A metodologia prevê uma explanação completa sobre os objetivos do trabalho a cada participante de forma individual e aplicação no próprio ambiente de trabalho, sem a presença de nenhum outro trabalhador e nem a chefia.

\subsubsection{Condições gerais de trabalho}

Nas condições de trabalho foram avaliados a existência de pausas no trabalho, o motivo pelo qual exerce a função, o cansaço, os riscos na jornada, o tipo de transporte até a frente de trabalho, os tempos de atraso no deslocamento para a frente de combate e suas complicações, a jornada de trabalho, a existência da vontade de mudar de atividade e os pontos que afetam o desempenho no serviço.

\subsubsection{Saúde}

Nas condições de saúde, aspectos como doenças que o trabalhador tem ou teve, lombalgias, possíveis doenças advindas da atividade, afastamentos por motivo de doenças, horas de sono diárias e patologias e, ou, distúrbios relacionados ao sono, cansaço ao iniciar a jornada de trabalho, rapidez e eficácia dos primeiros socorros quando estes se fizerem necessários e atitude psicológica foram avaliados de acordo com Silva (2001) e Fiedler (1998). Como o nível de escolaridade dos trabalhadores em geral era baixo, a metodologia previa uma explanação mais detalhada sobre situações como as possíveis doenças originadas do trabalho, tipos de cansaços mais comuns e primeiros socorros.

\subsubsection{Alimentação}

Na alimentação foram levantados dados sobre o número de refeições diárias, a qualidade, a quantidade e os horários de consumo.

\subsubsection{Treinamento e segurança}

Por último, treinamento e reciclagens na atividade foram levantados quanto à quantidade, qualidade e periodicidade dos treinamentos e reciclagens. Além disso, foram avaliados aspectos de segurança, como a disponibilidade, reposição e qualidade dos equipamentos de proteção individual (EPI). Foi questionado também sobre a exigência da aplicabilidade dos EPIs por parte dos coordenadores. Relativa ao treinamento, foi avaliada também a capacidade dos combatentes em compreender os aspectos teóricos fundamentais da prevenção e do combate ao fogo, além da compreensão da importância de tal atividade.

\subsection{Análise estatística}

Foi utilizado o teste qui-quadrado $\left(\mathrm{c}^{2}\right)$, com nível de significância de 5\%, para verificar as diferenças entre as brigadas quanto ao treinamento e às atividades de combate, através do programa StatSoft (2000). Os dados relativos ao treinamento incluíram a freqüência dos brigadistas que receberam treinamento, noções de segurança e primeiros socorros e necessidade de reciclagem. Os dados relativos às atividades de combate aos incêndios florestais incluíram a avaliação dos brigadistas quanto ao EPI utilizado, o horário preferencial de combate e a ocorrência de acidentes.

\section{RESULTADOS E DISCUSSÃO}

As condições de trabalho, treinamento, saúde e segurança a que estão submetidos os brigadistas das Unidades de Conservação da APA Gama Cabeça-deVeado são mostrados abaixo, por unidade.

\subsection{Brigada da Fazenda Água Limpa}

\subsubsection{Condições Gerais de Trabalho}

Os dados relativos aos 22 entrevistados na Fazenda Água Limpa mostraram que 13,04\% já exerceram trabalhos anteriores, e 86,9\% estavam no primeiro emprego. A função anterior exercida mais freqüente foi a de ajudante de pedreiro (13\%). Como motivo para terem saído do trabalho anterior, 39,1\% alegaram o fato de ter conseguido na FAL um trabalho melhor; 95,6\% estavam satisfeitos com as suas funções. O tempo médio de deslocamento da residência para o trabalho era de 38 minutos. O deslocamento da residência para o trabalho era feito com transporte do próprio brigadista em 39,1\% dos casos.

R. Árvore, Viçosa-MG, v.30, n.1, p.55-63, 2006 
A jornada de trabalho preferida pelos brigadistas era a de 8 horas, com intervalo para as refeições (86,9\%). Os brigadistas afirmaram serem indiferentes à necessidade esporádica de trabalho nos finais de semana e feriados (60,8\%). O ritmo de trabalho era controlado pelos próprios trabalhadores, segundo 60,8\% deles, e $95,6 \%$ tinham liberdade para realizar pequenas pausas durante o serviço.

Boa parte dos trabalhadores (47,8\%) considerou o seu trabalho muito repetitivo. A característica física do trabalho foi considerada pesada para $47,8 \%$ dos entrevistados, medianamente pesada para $43,5 \%$, muito pesada para $4,4 \%$ e leve para $4,3 \%$, sendo esses termos considerados pelos próprios brigadistas; $\quad 30,4 \%$ dos entrevistados exerciam a função por gosto pela atividade e 69,6\% por solicitação da administração da Fazenda Água Limpa.

A relação com os colegas de trabalho foi considerada ótima por $65,2 \%$ dos entrevistados e boa por $34,8 \%$ deles.

Todos os entrevistados disseram que se adaptavam facilmente às funções não desempenhadas regularmente.

A parte do trabalho de brigadista que dava maior satisfação era o combate direto com abafador, apontada por 47,8\% dos entrevistados. A menor satisfação foi o combate direto com bomba costal, apontada por $26,1 \%$. A função mais difícil e mais perigosa foi o combate com ocorrência de virada do vento, com 43,5\% das opiniões. De forma contraditória, embora tenha sido considerada por boa parte dos brigadistas como a parte do trabalho que dá maior satisfação, o combate direto com abafador foi considerado como a atividade mais cansativa, com $34,8 \%$ das respostas.

\subsubsection{Treinamento e Reciclagem}

Apenas 39,1\% dos entrevistados da Fazenda Água Limpa afirmaram ter recebido treinamento de brigadista. Todos que receberam treinamento o consideraram satisfatório, e eles tiveram em média nove dias de treinamento.

Ninguém sentiu dificuldades de atuar como brigadista ao término dos treinamentos, e $66,7 \%$ sentiram necessidade de relembrar ou aperfeiçoar alguma técnica. Entre todos os entrevistados, 65,2\% afirmaram que a Fazenda Água Limpa não realizava cursos ou treinamentos periódicos.

\subsubsection{Saúde}

A grande maioria dos brigadistas, representada por 91,3\%, revelou não ter tido nenhuma doença grave. Apenas dois brigadistas disseram que tiveram doenças mais graves: um teve pneumonia e o outro tinha fortes e freqüentes dores de cabeça - ambos representaram 8,7\% do total; $86,9 \%$ dos brigadistas afirmaram que atualmente não tinham problema de saúde algum, e 13\% afirmaram que tinham problemas de saúde; um apresentava problema na visão e dois, dores constantes na coluna vertebral.

O horário preferido para dormir era das 22 horas, com 43,5\% das opiniões dos brigadistas, e os horários preferidos para acordar foram às 5 e às 6 horas, com 30,4\% das opiniões. Em média, os entrevistados dormiam 8 horas por noite. No trajeto de casa ao trabalho, 73,9\% responderam que não sentiam sono durante esse deslocamento, $17,4 \%$ relataram que sentiam sono e $8,7 \%$ disseram que sentiam sono algumas vezes.

Todos os brigadistas concordaram com a importância da atividade física para o trabalho, e 43,47\% acharam que a freqüência ideal era de três vezes por semana, e o futebol e a corrida sendo considerados as atividades físicas mais efetivas, com $43,5 \%$ das opiniões cada.

Os brigadistas que não tiveram crise de lombalgia representaram $86,9 \%$ do total, e apenas $13 \%$ afirmaram que tiveram alguma crise de lombalgia nessa função.

\subsubsection{Segurança no Trabalho}

Na questão relativa a acidentes de trabalho, 82,6\% dos brigadistas responderam que nunca sofreram acidente no combate ao incêndio. No trabalho de brigadista, a situação considerada como a de maior risco de acidentes é o combate direto com abafador, com 45,8\% das opiniões na categoria de mais perigosa. A situação avaliada como a que gera menos perigo de acidentes é o rescaldo, com 56,5\% das opiniões; $88,9 \%$ dos brigadistas que receberam treinamento também receberam noções de segurança. Apenas 11,1\% consideraram essas noções como não satisfatórias. No caso de noções de primeiros socorros, somente 33,3\% dos brigadistas treinados as receberam, e todos as consideraram satisfatórias.

A Fazenda Água Limpa fornecia cantil para cada brigadista; a água era coletada em uma mina d’água dentro da fazenda e foi considerada pelos entrevistados 
de boa qualidade. Os brigadistas bebiam em média 1,5 L de água durante 1 hora de combate a um incêndio. Para 69,5\% dos brigadistas, a água já estava quente ou morna no momento em que iam consumir, ou seja, não havia recipientes térmicos para manter a água gelada.

O equipamento considerado como o mais desconfortável foi a bomba costal, com 82,6\% das respostas. O motivo do desconforto que ela causava era o seu peso excessivo, confirmado por 78,9\% dos entrevistados. A mochila costal e o abafador também foram alvos das reclamações $(17,4 \%)$.

Os equipamentos de proteção individual (EPIs) que a Fazenda Água Limpa fornecia não eram satisfatórios para 65,2\% dos brigadistas, porque não havia EPIs suficientes para todos.

A Fazenda Água Limpa fornecia botas para todos os seus funcionários, porém eram inadequadas para o combate a incêndios, pois tinham o cano curto. Não havia calças e camisas próprias para combate, e, entre os brigadistas que já usaram a proteção ocular, 40\% consideraram que ela oferecia pouca proteção contra a fumaça e o calor. Entre os que já utilizaram a máscara respiratória, 55,5\% a consideraram confortável. A maioria dos brigadistas $(52,2 \%)$ afirmou nunca terem usado esses EPIs. Não foram relatados problemas respiratórios pelos brigadistas, apesar do limitado uso do equipamento de proteção (máscara).

A maior parte dos brigadistas (60,9\%) considerou que a reposição dos EPIs não era adequada; deveria ser feita com mais freqüência, uma a duas vezes por ano, preferencialmente antes do período da seca; 73,9\% dos brigadistas preferiam combater incêndios durante o dia. A principal dificuldade no combate durante o dia era o calor representado por $65,2 \%$ das opiniões; à noite, era a pouca visibilidade que dificultava o deslocamento e aumentava o risco de acidentes (95,6\%).

O comentário mais freqüente dos brigadistas foi um pedido para que a Brigada adquirisse mais equipamentos e ferramentas específicos para o combate e de melhor qualidade. Outras sugestões importantes foram a de aquisição de um caminhão-pipa, alimentação adequada durante o combate, maior acesso a informações sobre novas tecnologias e novos métodos de combate e a regularização da função de brigadista.

\subsection{Brigada da Reserva Ecológica do IBGE}

\subsubsection{Condições Gerais de Trabalho}

Dos 15 brigadistas do IBGE entrevistados, apenas 23,1\% não trabalharam em lugar algum antes de fazêlo no IBGE, sendo a função exercida anterior mais comum a de pedreiro $(23,1 \%)$.

O fato de terem conseguido trabalho no IBGE foi o motivo de saída do trabalho anterior de $80 \%$ dos entrevistados. Todos estavam satisfeitos em suas funções atuais. O tempo médio de deslocamento de casa ao trabalho era em média de 66 minutos; 76,9\% dos brigadistas tinham transporte próprio para o deslocamento.

A maior parte dos brigadistas (53,9\%) preferia uma jornada de trabalho de 8 horas diárias com intervalo para o almoço e 30,8\% preferia 6 horas ininterruptas de trabalho e 15,4\% tinham preferência por uma jornada de 24 horas de serviço por 72 de descanso.

Trabalhos de combate aos sábados, domingos e feriados agradavam a 7,7\% dos brigadistas, 15,4\% se disseram insatisfeitos e $76,9 \%$ foram indiferentes.

O controle sobre o ritmo de trabalho foi consenso para $76,9 \%$ dos brigadistas, $7,7 \%$ não controlavam e $15,4 \%$ não souberam responder. Todos tinham liberdade para realizar pequenas pausas durante o serviço. $\mathrm{O}$ trabalho no IBGE era muito repetitivo para $38,5 \%$ e moderadamente repetitivo para 7,7 \% e não repetitivo para 53,9\% dos entrevistados.

O trabalho de brigadista era considerado pesado por $38,5 \%$ deles, medianamente pesado por $46,2 \%$ e leve por $15,4 \%$. A maioria, representada por $84,6 \%$, trabalhava como brigadista porque gostava da função e $15,4 \%$ o faziam por solicitação do IBGE.

A relação com os colegas foi considerada ótima por $84,6 \%$ dos brigadistas e boa por $15,4 \%$. Todos afirmaram não ter dificuldade alguma para se adaptar a outras funções quando necessário.

No combate a incêndios, a parte mais satisfatória era dividida entre o manuseio da mangueira do caminhãopipa e a condução do caminhão-pipa, com 23,1\% das opiniões cada. A parte que dava menos satisfação era o combate direto com abafador, com 30,8\%. A parte considerada como a mais difícil era a situação de fogo intenso com $30,8 \%$, e a parte considerada como a mais

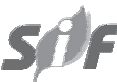

R. Árvore, Viçosa-MG, v.30, n.1, p.55-63, 2006 
perigosa era o momento em que ocorria virada do vento, com 38,5\% das respostas. Por fim, a parte considerada como a mais cansativa foi o combate direto com abafador, relatado por $23,1 \%$ dos brigadistas.

\subsubsection{Treinamento e Reciclagem}

Apenas um brigadista afirmou não ter recebido treinamento, representando $7,7 \%$ do total, enquanto a grande maioria $(92,3 \%)$ recebeu treinamento, tendo em média 23 dias de treinamento.

Todos consideraram o treinamento satisfatório e afirmaram não ter dificuldade alguma de atuar como brigadista após o término dos treinamentos, e 58,3\% responderam não sentirem a necessidade de relembrar ou aperfeiçoar alguma técnica de combate a incêndios; enquanto $41,7 \%$ afirmaram que gostariam de realizar reciclagem das técnicas aprendidas, e 69,2\% dos brigadistas afirmaram que a reserva não realizava cursos ou treinamentos com constância.

\subsubsection{Saúde}

Do total de brigadistas entrevistados, 30,8\% tiveram alguma doença mais grave no passado (malária, úlcera, problemas na próstata e diabetes). Atualmente, 84,6\% não tiveram problema algum de saúde, e 15,4\% apresentaram problemas de saúde, sendo um caso de ansiedade e outro de problemas na coluna vertebral.

A média de horas de sono por noite era de oito horas. Apenas um brigadista afirmou sentir sono durante o trajeto de casa para o trabalho.

A importância da atividade física para a função de brigadista foi consenso entre todos, e a freqüência ideal para 53,8\% seria quatro vezes por semana. O futebol foi considerado a atividade física mais efetiva para a função de brigadista, com 38,5\% das respostas.

Do total de brigadistas, 61,5\% nunca apresentaram crise de lombalgia, e $38,5 \%$ tiveram pelo menos uma crise de lombalgia.

\subsubsection{Segurança no Trabalho}

Apenas um brigadista sofreu acidente em um combate direto e $46,1 \%$ alegaram ter visto acidentes durante o combate. A situação considerada mais perigosa por $61,5 \%$ dos brigadistas foi o combate direto com abafador, enquanto a situação que apresentou o menor risco de acidentes foi o rescaldo, com 69,2\% das opiniões.
Todos os brigadistas que receberam treinamento tiveram noções de segurança e de primeiros socorros, e todos consideraram essas noções satisfatórias.

A reserva do IBGE fornecia cantil para os brigadistas durante os combates, e a água que eles consomiam era coletada em uma mina d'água localizada dentro da reserva. É considerada de boa qualidade, e eles bebiam em média 1,3 L durante uma hora de combate. A maior parte dos brigadistas afirmou que a água que consomiam durante o combate permanecia fria, com $46,1 \%$ das opiniões.

A bomba e a mochila costal foram consideradas as ferramentas mais desconfortáveis, com 69,2\% das respostas, e todos concordaram que o peso é o motivo do desconforto.

Apenas 30,8\% consideraram os EPIs fornecidos pelo IBGE satisfatórios, enquanto 69,23\% conceberam os EPIs como não-satisfatórios, justificando-se pela falta de equipamentos.

O EPI mais desconfortável era a máscara respiratória, com 15,4\% das respostas. Porém, 61,5\% nunca usaram máscara. A proteção ocular nunca foi usada por $69,2 \%$ dos brigadistas, e as luvas nunca foram utilizadas por $46,2 \%$ desses brigadistas. A reposição dos EPIs não era adequada, segundo $61,5 \%$ do total.

Apenas um brigadista preferia o combate noturno, em função da temperatura mais amena. As principais dificuldades no combate diurno foram os ventos, com $38,5 \%$ das respostas; e o calor, com 53,9\%. A principal dificuldade no combate noturno foi a pouca visibilidade.

Os comentários e sugestões mais presentes foram em relação à formalização da brigada e a necessidade de equipamentos e ferramentas adequados ao combate e de melhor qualidade.

\subsection{Brigada do Jardim Botânico de Brasília}

\subsubsection{Condições Gerais de Trabalho}

Dos 16 brigadistas entrevistados no Jardim Botânico de Brasília (JBB), somente um não trabalhou em outro local antes. Uma parcela de 33,3\% deixou o último emprego por ter conseguido trabalho no JBB, e 13,3\% foram transferidos da extinta Fundação Zoobotânica.

Todos os entrevistados estavam satisfeitos em suas funções atuais. O tempo médio de deslocamento da residência dos brigadistas até o trabalho era de 
54 minutos; $60 \%$ destes tinham transporte próprio, sendo $88,9 \%$ deles carros e $11,1 \%$, motos.

A preferência em relação à jornada de trabalho era para a jornada de oito horas diárias com intervalo para o almoço, com $86,7 \%$ das respostas; e $13,3 \%$ preferiam trabalhar seis horas ininterruptas.

Quanto ao trabalho realizado aos sábados, domingos e feriados, $46,7 \%$ se disseram indiferentes, $33,3 \%$ se mostravam insatisfeitos porque atrapalhava o descanso e $20 \%$ estavam satisfeitos com essa situação.

Apenas um brigadista afirmou não ter controle sobre o seu ritmo de trabalho. Todos afirmaram que tinham liberdade para realizar pequenas pausas durante o serviço; $80 \%$ consideraram as suas funções bastante repetitivas, e $20 \%$ responderam que estas variavam muito a cada dia de serviço. O trabalho de brigadista foi avaliado como muito pesado por $13,3 \%$ dos entrevistados, pesado por $46,7 \%$, medianamente pesado por $33,3 \%$ e leve por $6,7 \%$ do total.

Os brigadistas que afirmaram trabalhar nessa função por gostarem equivalem a $53,3 \%$ do total, e os que trabalhavam por solicitação do JBB foram 46,7\%.

A relação com os colegas de trabalho foi considerada ótima por $80 \%$ dos brigadistas e boa por $20 \%$ deles. Todos os brigadistas do JBB afirmaram que se adaptavam facilmente às outras funções que lhes eram designadas; 26,7\% deles consideraram como a parte mais satisfatória do trabalho de brigadista o combate direto com abafador, e $20 \%$ consideraram o combate direto em geral como a parte menos satisfatória. A parte mais difícil foi o combate de fogo em matas de galeria, com 26,7\%; a parte mais perigosa era a virada do vento, com $60 \%$ das respostas, e a parte mais cansativa era o combate em áreas de aclive como morros, com $26,7 \%$ das respostas.

\subsubsection{Treinamento e Reciclagem}

Apenas um brigadista afirmou não ter recebido treinamento, e, entre os que receberam, 92,8\% consideraram-no satisfatório; eles receberam em média 31 dias de curso.

Ninguém sentiu dificuldades de atuar como brigadista após os treinamentos; $50 \%$ sentiam necessidade de relembrar e aperfeiçoar algumas técnicas de combate, e a outra metade dispensava a reciclagem; $40 \%$ dos brigadistas afirmaram que o JBB realizava cursos e treinamentos periódicos, 26,7\% disseram que às vezes ocorriam cursos ou treinamentos e 33,3\%, que não ocorriam.

\subsubsection{Saúde}

Entre todos os brigadistas, $80 \%$ nunca tiveram doença. Os demais tiveram problemas de sinusite, pneumonia e úlcera.

Atualmente, 66,7\% não tinham problema de saúde. Entre os brigadistas que têm problemas, $80 \%$ sofriam de pressão alta, e $20 \%$ apresentavam problemas renais e na coluna vertebral.

Os brigadistas dormiam em média oito horas por noite. No trajeto de casa para o trabalho, apenas um brigadista afirmou que sentia sono. Todos consideraram a atividade física importante para o trabalho de brigadista, com uma freqüência de duas vezes por semana, defendida por $53,3 \%$. A atividade física considerada como mais efetiva foi a corrida, com $53,3 \%$ das respostas; $60 \%$ nunca tiveram crise de lombalgia.

\subsubsection{Segurança no Trabalho}

Treze vírgula três por cento dos brigadistas do JBB já sofreram acidente na função, enquanto 46,7\% já presenciaram algum.

A situação considerada de maior risco de acidentes na atividade de brigadista foi a operação de contrafogo, com $40 \%$ das opiniões na categoria de mais perigosa. A situação que oferecia menos risco de acidentes foi o rescaldo, com todas as opiniões possíveis na categoria de risco nulo.

Entre os que receberam treinamento, todos tiveram noções de segurança e de primeiros socorros; 7,1\% não consideraram as noções de segurança satisfatórias, e $14,3 \%$ não consideraram as de primeiros socorros satisfatórias.

O JBB fornecia cantil para todos, e a água que eles consomiam era a fornecida pela CAESB. Os brigadistas do JBB bebiam em média 3,1 L de água durante uma hora de combate, 53,3\% deles afirmaram que a água já estava quente no momento de consumo devido à falta de recipientes térmicos.

A bomba costal foi considerada o equipamento mais desconfortável, segundo 80\% dos brigadistas, seguida da mochila costal (66,7\%) e do abafador (53,3\%). O principal motivo do desconforto foi o peso, conforme a opinião de 53,3\% dos brigadistas.

R. Árvore, Viçosa-MG, v.30, n.1, p.55-63, 2006 
Os EPIs não foram satisfatórios para 66,7\% dos entrevistados. Alguns equipamentos básicos, como calça e camisas, foram considerados como desconfortáveis, por serem inadequados para a atividade; 53,3\% dos brigadistas que já utilizaram a proteção ocular consideraram-na desconfortável, por ineficiência e incômodo. A máscara respiratória foi considerada desconfortável por 13,3\% deles, enquanto as luvas, desconfortáveis por 46,7\% deles, por serem incômodas e inadequadas; 73,3\% consideraram a reposição dos EPIs inadequada. O combate diurno foi preferido por $86,7 \%$ dos brigadistas. O calor e o vento eram as principais dificuldades do combate diurno, ambas com $60 \%$ das respostas. A pouca visibilidade foi a principal dificuldade do combate noturno.

Os brigadistas do JBB levantaram a questão da necessidade de regulamentação das Brigadas e atentavam para a falta de material de segurança e a necessidade de se criar um fundo específico para as Brigadas no repasse das verbas concedidas pelo governo.

\subsection{Análise de Diferenças entre as Brigadas}

Nas Figuras 1 e 2, mostra-se uma comparação dos principais fatores de diferença entre as brigadas em relação aos itens de treinamento, combate e satisfação com equipamentos. Nota-se, nessas figuras, que o baixo índice de treinamento e a baixa participação em cursos de primeiros socorros dos brigadistas da Fazenda Água Limpa provavelmente tinham levado a um maior índice de acidentes (Figura 1). As considerações sobre a falta de equipamentos de proteção individual e reposição inadequada foram constantes em todas as brigadas avaliadas (Figura 2).

De acordo com a avaliação estatística, foram observadas diferenças significativas $\left(c^{2}=37,27 ; \mathrm{p}<\right.$ 0,05 ) entre as brigadas nos itens relativos ao treinamento (noções de primeiros socorros, número de treinados, necessidade de reciclagem e noções de segurança). O item relativo ao número de brigadistas que receberam treinamento foi importante para as diferenças, considerando-se que havia grande deficiência de treinamento para os brigadistas da Fazenda Água Limpa. De qualquer forma, as três brigadas analisadas necessitavam de treinamentos complementares ao curso básico que foi oferecido, assim como já foi observado nas brigadas no Parque Nacional Serra da Canastra (FIEDLER e MEDEIROS 2002), considerando-se a necessidade constante de reciclagens e o surgimento de novos métodos e tecnologias na área.

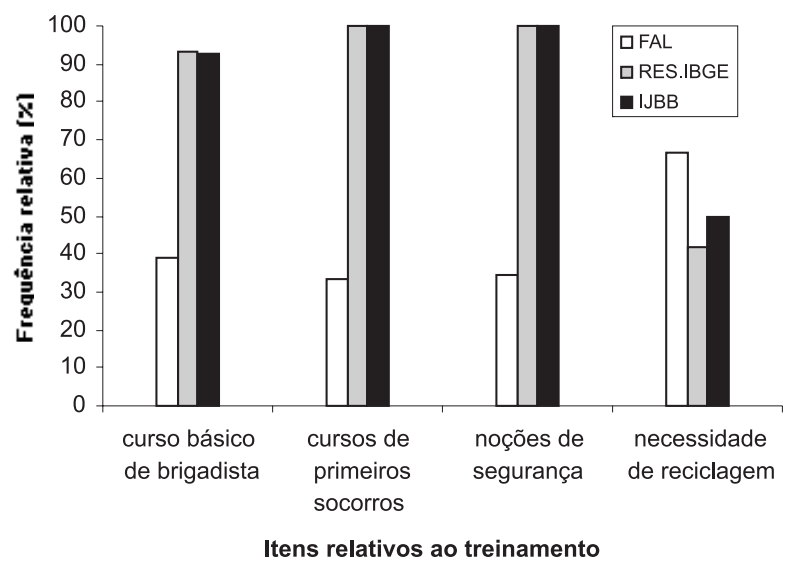

Figura 1 - Diferenças entre as brigadas quanto a aspectos de treinamento.

Figure 1 - Differences among fire crews related to training aspects.

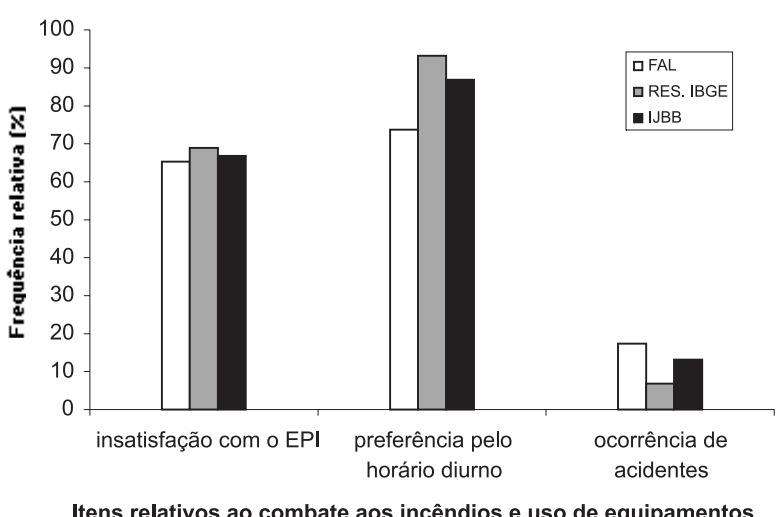

Figura 2 - Diferenças entre as brigadas quanto a aspectos de combate aos incêndios e equipamentos.

Figure 2-Differences among fire crews related to fire fighting and equipments.

Para os itens relativos às atividades de combate aos incêndios, incluindo-se insatisfação com o EPI, preferência pelo horário diurno e ocorrência de acidentes, não houve diferenças significativas $\left(c^{2}=0,18 ; p>0,05\right)$.

Particularmente, a insatisfação generalizada dos brigadistas com o EPI demonstrou a necessidade de adaptação e aquisição de equipamentos mais confortáveis e práticos. A carência e a inadequação de equipamentos também parecem ser comuns a muitas brigadas de combate a incêndios florestais no Brasil, sendo esse item um dos principais responsáveis pelo baixo grau de eficiência das atividades de combate 
(FIEDLER e MEDEIROS, 2002; MEDEIROS 2002). Afalta de equipamentos motorizados como caminhões-pipa, relatada pela brigada da Fazenda Água Limpa, torna as atividades de combate limitadas por equipamentos manuais de eficiência comparativamente reduzida. Além disso, a ocorrência de acidentes em situações de combate aos incêndios florestais está muitas vezes relacionada à falta de equipamentos de qualidade e específicos para esse tipo de atividade (IBAMA, 1999).

Assim, ambas as brigadas analisadas devem apresentar sérias limitações nas atividades de combate, devido aos problemas relativos aos equipamentos.

\section{CONCLUSÕES}

De acordo com os resultados obtidos, concluise que:

- A brigada da Fazenda Água Limpa mostrou alto porcentual de trabalhadores sem problemas de saúde $(91,3 \%)$ e alto índice de acidentes $(17,4)$, alto nível de satisfação e baixo índice de treinamento (39,1\%). Há necessidades de melhoria na reposição de equipamentos de proteção individual e estabelecimento de reciclagens mais periódicas.

- A brigada da reserva ecológica do IBGE mostrou alto porcentual de treinados $(92,3 \%)$, alto nível de satisfação e baixo nível de acidentes (7,7\%). No entanto, deve haver maior investimento do órgão em reciclagens (69,2\% nunca realizaram) e maior atenção para o alto índice de trabalhadores, que já tiveram doenças (30,8\%). O tempo de treinamento obtido pelos brigadistas não foi igual nas três brigadas e também foi insuficiente para aumentar a eficiência de atuação, considerandose a necessidade de estudos complementares à função.

- Na brigada do Jardim Botânico de Brasília, 80\% não tiveram problemas de saúde, e 92,8\% foram treinados. No entanto, o nível de acidentes foi o segundo maior entre os registrados nas três brigadas (13,3\%).

A grande maioria dos brigadistas nas três Unidades de Conservação ressaltou a questão da necessidade de regulamentação das Brigadas e atentou para a inadequada reposição dos equipamentos de proteção individual e ferramentas de combate.

- O equipamento de combate considerado mais desconfortável pelos brigadistas foi a bomba costal em função das suas condições anatômicas e peso.
- As brigadas analisadas apresentaram diferenças significativas, quanto ao treinamento, e não exibiram diferenças significativas quanto às atividades de combate.

\section{REFERÊNCIAS BIBLIOGRÁFICAS}

FIEDLER, N. C. Análise de posturas e esforços despendidos em operações de colheita florestal. 1998. 106 f. Tese (Doutorado em Ciência Florestal) - Universidade Federal de Viçosa, Viçosa, 1998.

FIEDLER, N. C.; RODRIGUES, T. O.; MEDEIROS, M.B. Avaliação das condições de trabalho de brigadistas de combate a incêndios florestais. Revista Floresta, v.34, n.2, p. 89-94, 2004.

GRANDJEAN, E. Manual de ergonomia adaptando o trabalho ao homem. Porto Alegre: Artes Médicas, 1998. 338p.

IBAMA. Manual de prevenção e combate aos incêndios florestais. Brasília: 1999. 180 p. Não Publicado.

MinetTi, L.J. Análise de fatores operacionais e ergonômicos na operação de corte florestal com motosserra. 1996. 211f. Tese (Doutorado em Ciência Florestal) - Universidade Federal de Viçosa, Viçosa, 1996.

MEDEIROS, M. B. Manejo do Fogo em Unidades de Conservação do Cerrado. Boletim do Herbário Ezechias Paulo Heringer, n.10, p.76-89, 2002.

MEDEIROS, M.B.; FIEDLER, N.C. Incêndios florestais no Parque Nacional da Serra da Canastra.: desafios para a conservação da biodiversidade. Revista Ciência Florestal, v. 14, n. 2, p. 157-168, 2004.

SILVA, J. C. et al. Avaliação de brigadas de incêndios florestais em Unidades de Conservação. Revista Árvore, v. 27, n. 1, p. 95-104, 2003.

STATSOFT INC. Statistica. Tulsa: 2000. 326p.

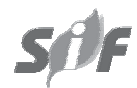

R. Árvore, Viçosa-MG, v.30, n.1, p.55-63, 2006 